Supporting Information

for

\title{
His-Mediated Reversible Self-Assembly of Ferritin Nanocage through Two Different Switches for Encapsulation of Cargo \\ Molecules
}

Chunkai Gu, Tuo Zhang, Chenyan Lv, Yu Liu, Yingjie Wang, Guanghua Zhao*

College of Food Science \& Nutritional Engineering, China Agricultural University, Key

Laboratory of Functional Dairy, Ministry of Education, Beijing 100083, China

*Corresponding author: Guanghua Zhao, E-mail: gzhao@ cau.edu.cn, Phone: 0086-10-62738737 


\section{Supporting Information}

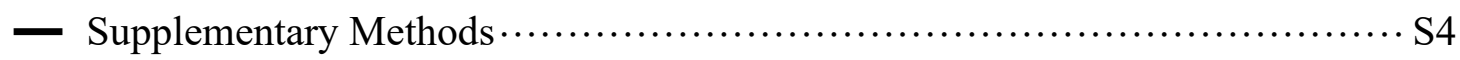

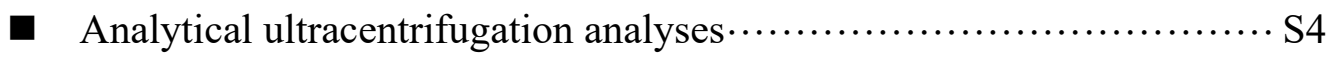

- Transmission Electron Microscopy (TEM) Imaging …................. S4

- Calculation of efficiencies for the reconstruction of protein nanocages *. S4

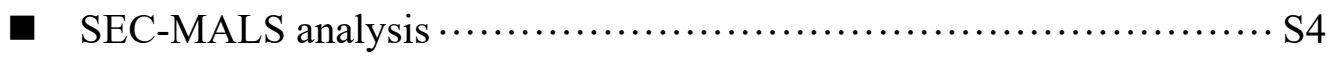

- Isothermal titration calorimetry (ITC) analysis ……................ S4

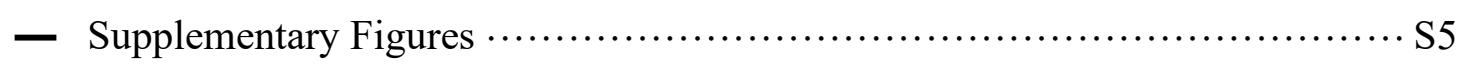

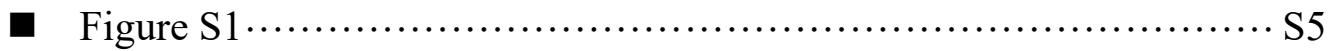

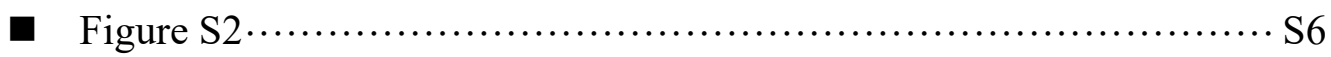

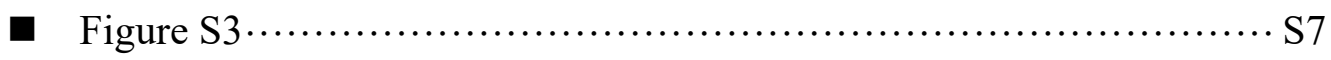

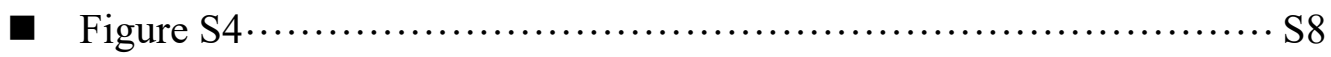

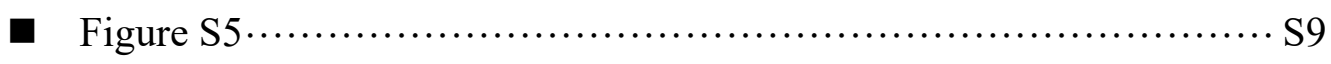

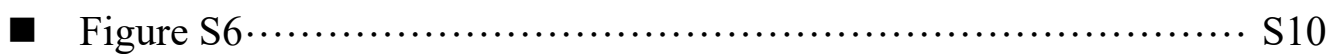

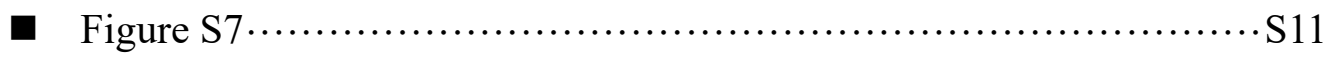

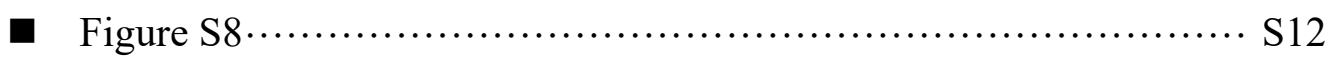

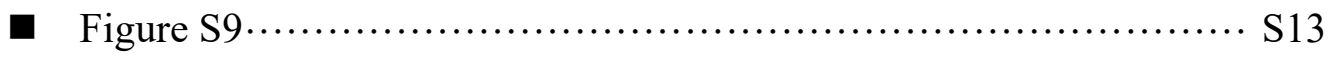

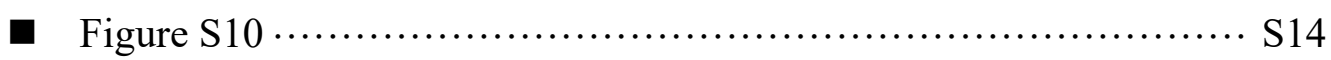

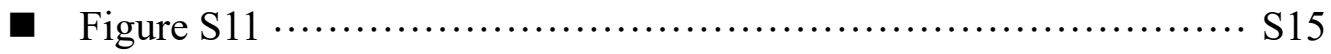

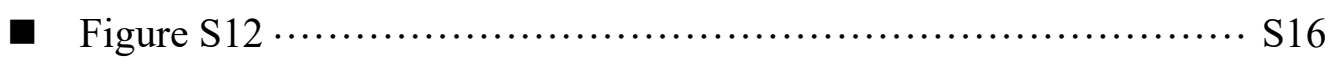

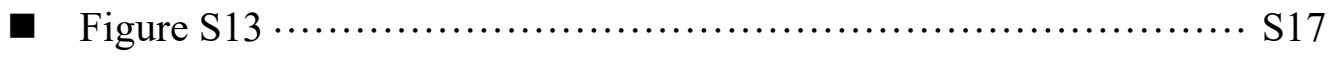

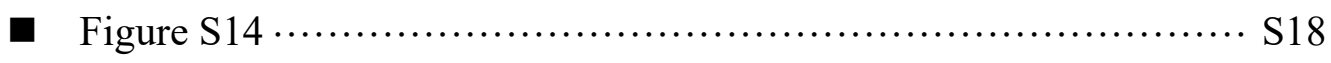

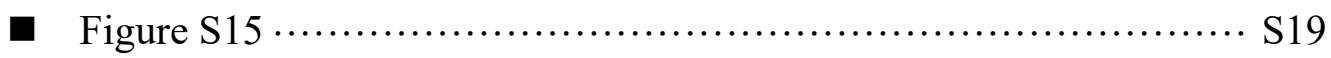

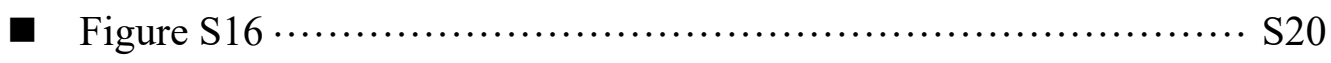

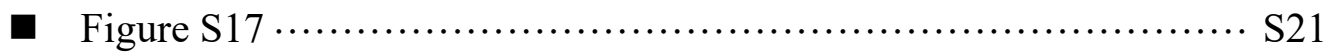

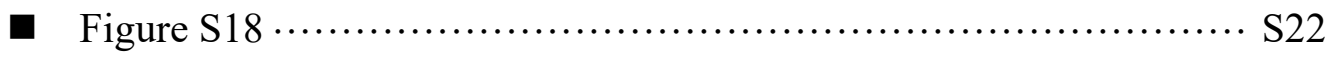

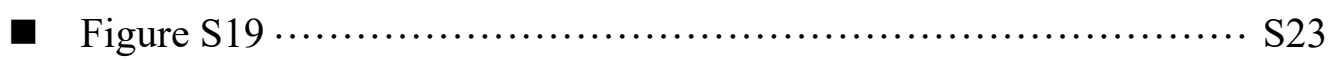

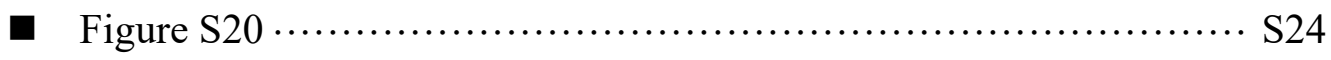




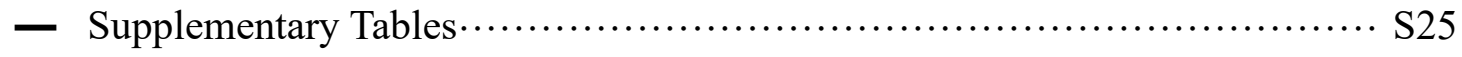

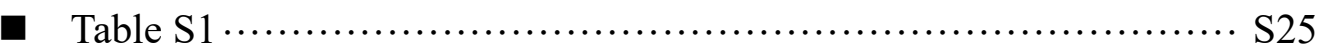

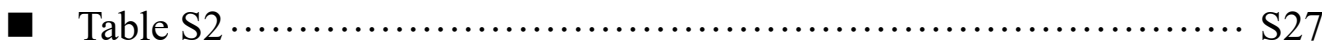




\section{Supplementary Methods}

Analytical ultracentrifugation analyses. Analytical ultracentrifugation analyses were performed at $4{ }^{\circ} \mathrm{C}$ in a Beckman Optima XPN-100 analytical ultracentrifuge (Beckman Coulter). Experiments were conducted at 20,000 r.p.m. Protein samples were in $20 \mathrm{mM}$ Tris- $\mathrm{HCl}, \mathrm{pH}$ 7.5. Protein concentrations were $0.5 \mathrm{mg} / \mathrm{mL}$.

Transmission Electron Microscopy (TEM) Imaging. His6-HuHF and His6-SF samples $(0.5 \mu \mathrm{M})$ were deposited onto carbon-coated copper grids. After a 2-min incubation, the excess solution was wicked away with filter paper. The samples were stained using $2 \%$ uranyl acetate for $2 \mathrm{~min}$. After drying, the grids were imaged on a Hitachi H-7650 scanning electron microscope at $80 \mathrm{kV}$.

Calculation of efficiencies for the reconstruction of protein nanocages. His 6 -HuHF tetramers were assembled into nanocages induced by the methods of PRNT and MRNT. As control, rHuHF protein nanocages were constructed by adjusting $\mathrm{pH}$ from 2.0 to 7.0 as previously reported. The tetramers (His6-HuHF) and dimers (rHuHF) that did not participate in the reconstruction of nanocages were separated with ultrafiltration centrifuge tube $(100 \mathrm{kDa}, 4000 \mathrm{rpm}, 15 \mathrm{~min}$. The $\sim 80$ $\mathrm{kDa}$ tetramers did not go through a $100 \mathrm{kDa}$ cut off ultrafiltration tube. The efficiency of reconstructed protein nanocage (\%) was calculated according to the mass amount of reconstructed ferritin nanocage / the total mass amount of protein used $\times 100 \%$. Protein concentrations were determined according to the Lowry method with bovine serum albumin (BSA) as standard.

SEC-MALS analysis. SEC-MALS experiment for $\mathrm{His}_{6}$-HuHF tetarmers was performed using a DAWN-HELEOS S6 II detector (Wyatt Technologies) coupled to a Superdex 200 column (GE Healthcare) in buffer ( $20 \mathrm{mM}$ Tris, $100 \mathrm{mM} \mathrm{NaCl}, \mathrm{pH}=7.5$ ) with flow rate $0.4 \mathrm{~mL} / \mathrm{min}$. His 6 -HuHF $(1.0 \mathrm{mg} / \mathrm{ml})$ was injected and data were analyzed using ASTRA 6 software (Wyatt Technologies) to determine the weight averaged molecular mass.

Isothermal titration calorimetry (ITC) analysis. ITC measurements were carried out at $25{ }^{\circ} \mathrm{C}$ using a TA Instruments Nano ITC with a $270 \mu \mathrm{L}$ sample cell, $50 \mu \mathrm{L}$ titration syringe, $2.0 \mu \mathrm{L}$ injection volumes and $360 \mathrm{~s}$ interval between injections to ensure complete equilibration, as dictated by the experiment. Before each titration, all solutions were degassed thoroughly under vacuum. The solution in the sample cell was stirred at $300 \mathrm{rpm}$ to ensure rapid mixing of the titrant upon injection. 


\section{Supplementary Figures}

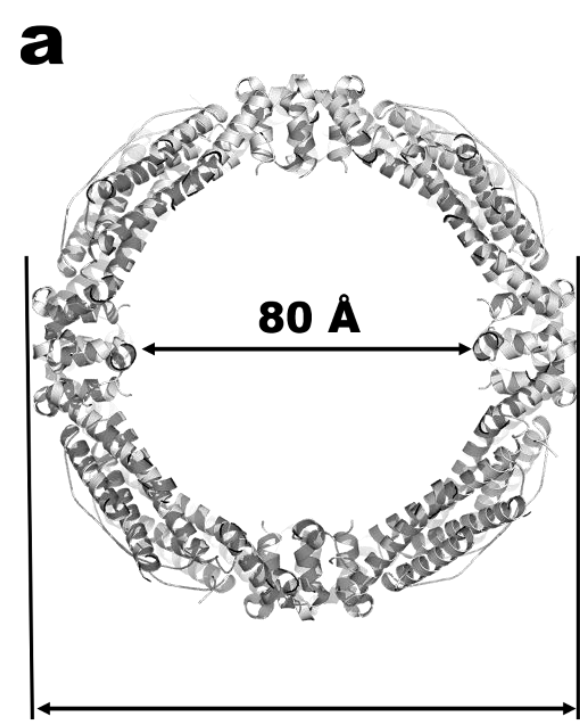

$120 \AA$ b
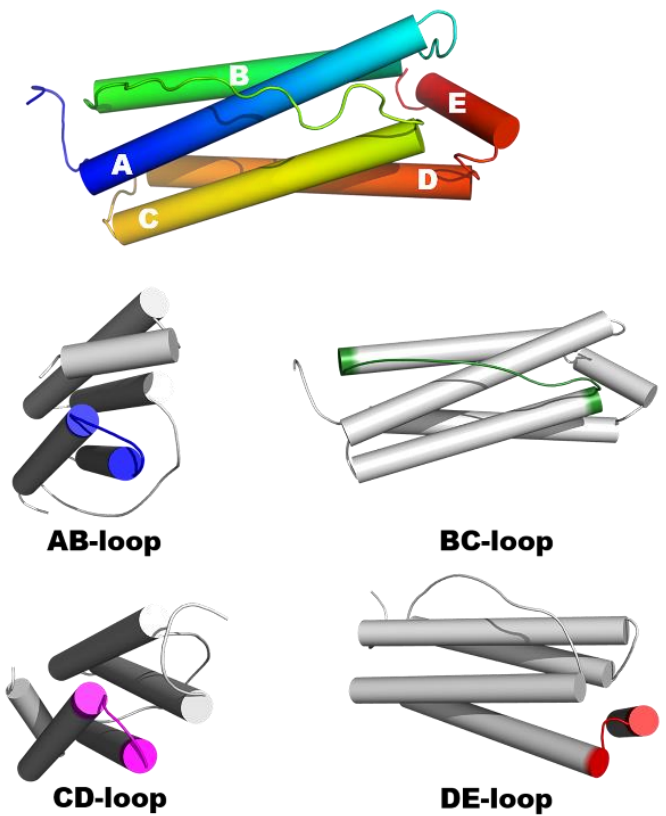

Figure S1. The structure of recombinant human H-chain ferritin (rHuHF). (a) Ribbon diagram of the cross-section structure of rHuHF, PDB $2 \mathrm{FHA}$, shows its inner and outer diameters of $\sim 80$ and $120 \AA$ A. (b) Diagram of the subunit structure of rHuHF. Each subunit is composed of four long $\alpha$ helix (A, B, C, and D), a short E-helix, three short loops (AB, CD, and DE), and a long BC loop. 
a
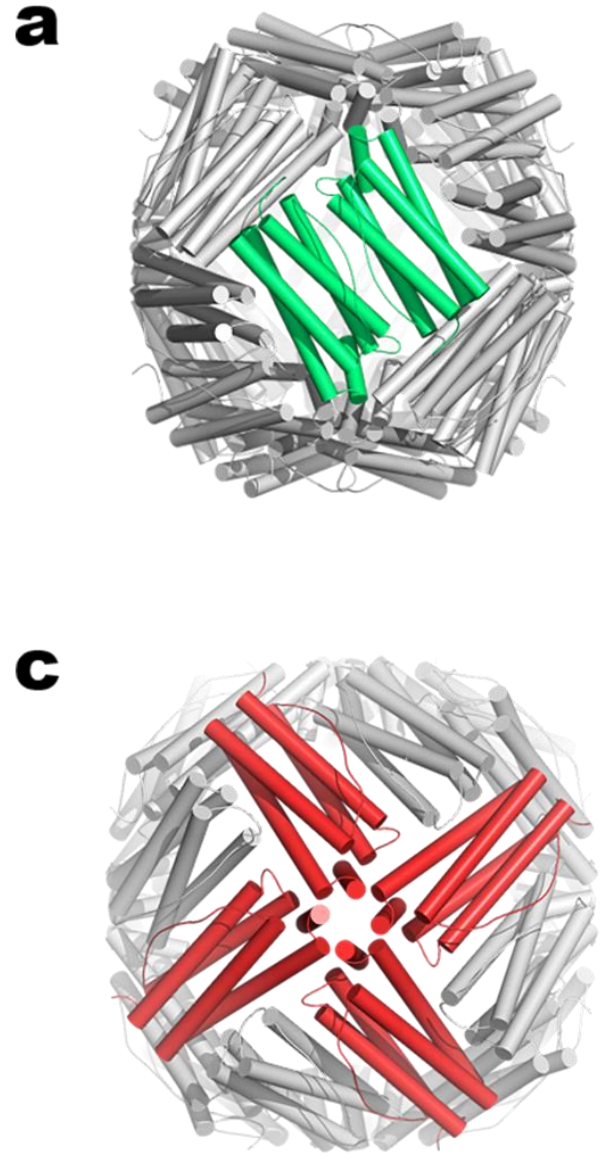

b

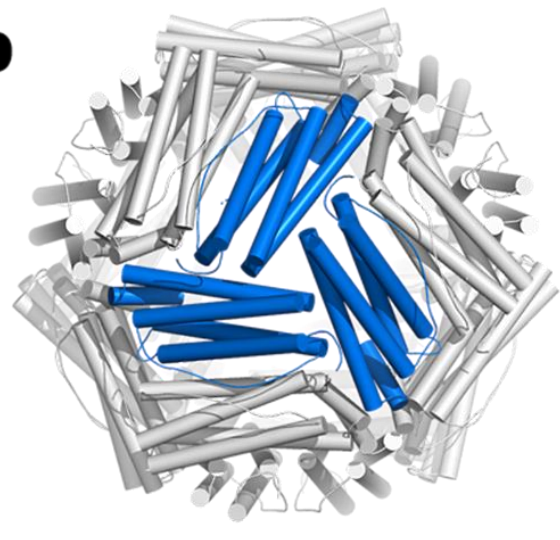

d

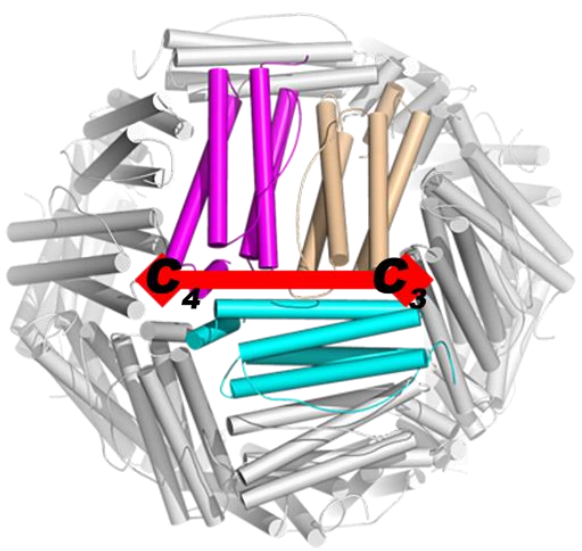

Figure S2. Four key interfaces are responsible for self-assembly of ferritin nanocage. (a) The $C_{2}$ interface of ferritin is highlighted in green. (b) The $C_{3}$ interface of ferritin is highlighted in blue. (c) The $C_{4}$ interface of ferritin is highlighted in red. (d) The $C_{3}-C_{4}$ interface of ferritin is between the $C_{3}$ and $C_{4}$ axes. 
Hisı -HuHF

His $-\mathrm{HuHF}$

Hiss-HuHF

His 6 -HuHF $\mathrm{His}_{6}-\mathrm{SF}$

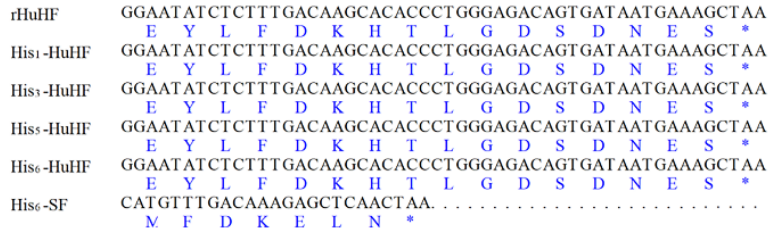

rHuHF

Hiss-HuH

His 6 -SF

ATGACGACCGCGTCCACCTCGCAGGT GCGCCAGAACT ACCACCAGGACTCAGAGGCCGCCATCAACCGCCAGATCAACCT GGAGCTCTACGCCTCCTACG 100 $\underset{A T G A C G A C C G C G T C C A C C T C G C A G G T G C G C C A G A A C T}{A}$ ACCACCAGGACTCAGAGGCCGCCATCAACCGCCAGATCAACCTGGAGCTCTACGCCTCCTACG $_{100}$

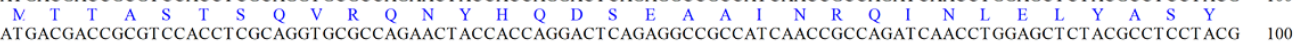

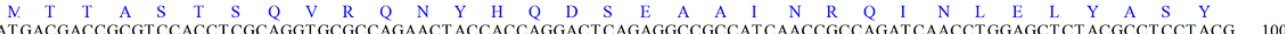

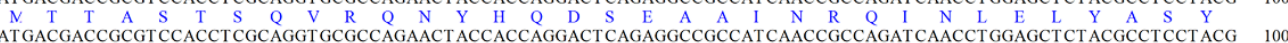

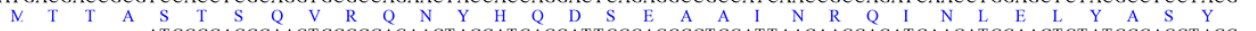
ATGGCCAGCCAAGTCCGCCAGAACT ACCATGAGGATTGCGAGGCCTCGATTAACAAGCAGATCAACATGGAACTGTATGCGAGCTACG 88
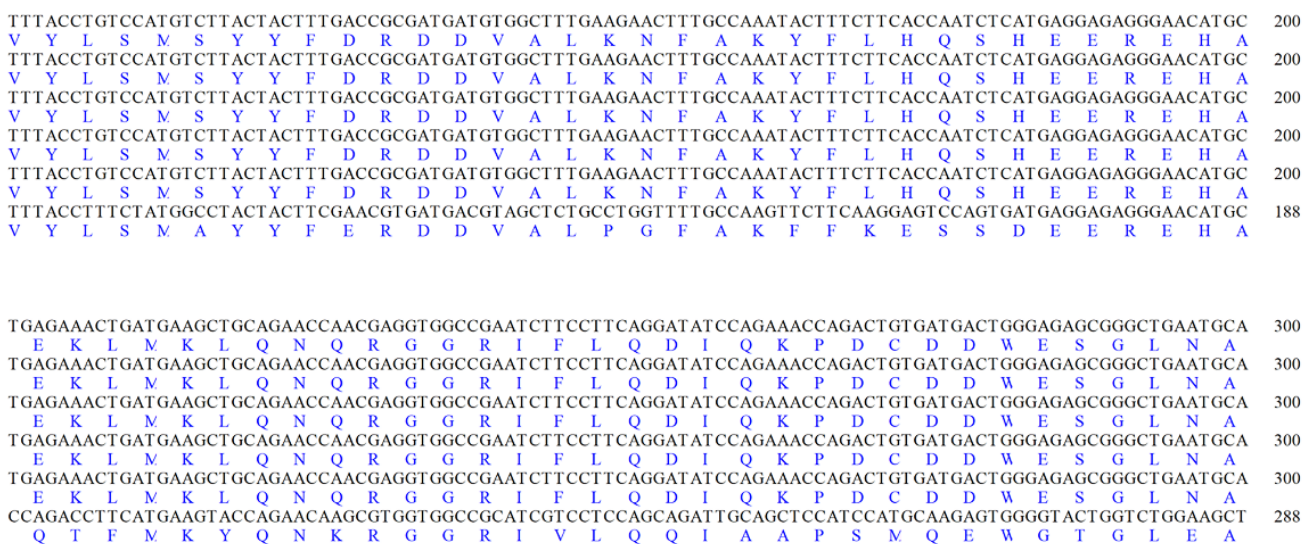

ATGGAGT GT GCAT TACATT GGAAAAAAAT GT GAATCAGT CACT ACT GGAACT GCACAAACT GGCCACT GACAAAAAT GACCCCCATTTGT GT GACTTCA 400

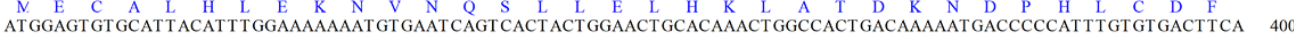

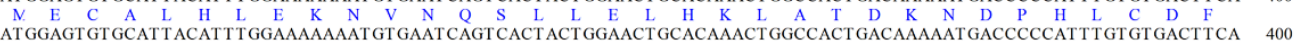

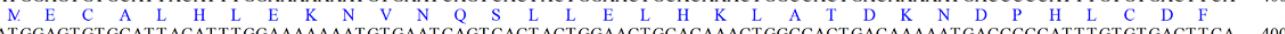

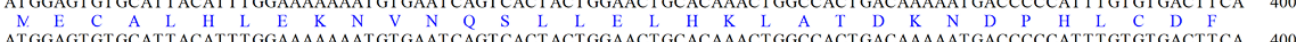
ATGGAGT GT GCATTACATT GGAAAAAAATGTGAATCAGTCACTACTGGAACTGCACAAACTGGCCACTGACAAAAATGACCCCCATTTGT GT GACTTCA 400

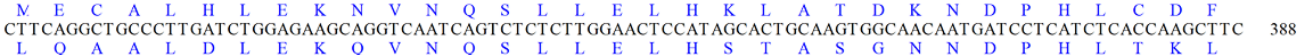

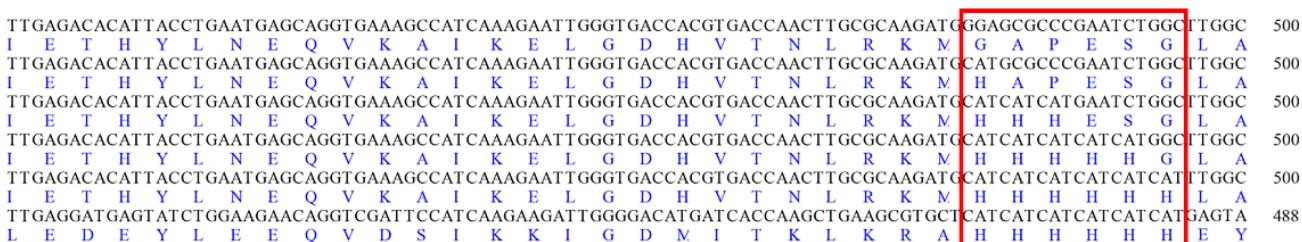

Figure S3. Nucleotide sequences alignment of rHuHF, His $1-\mathrm{HuHF}$, His 3 -HuHF, Hiss-HuHF, His $6^{-}$

HuHF and His $_{6}-\mathrm{SF}$ subunits. Mutation sites were highlighted within a red box. rHuHF represents recombinant human heavy chain ferritin, and SF represents a shrimp (Marsupenaeus japonicus) ferritin. 


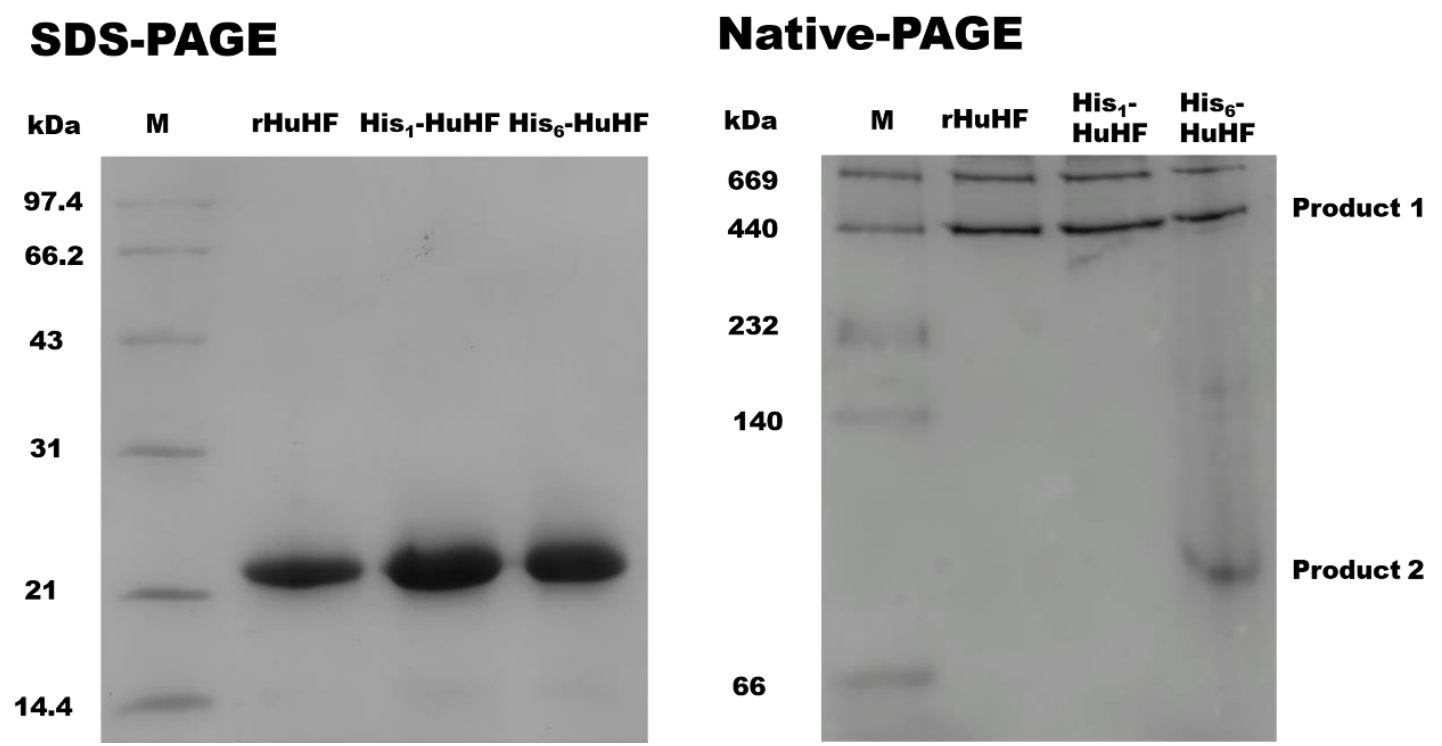

Figure S4. SDS-PAGE and native-PAGE electrophoretic characterization of rHuHF, His 1 -HuHF and His6-HuHF. 


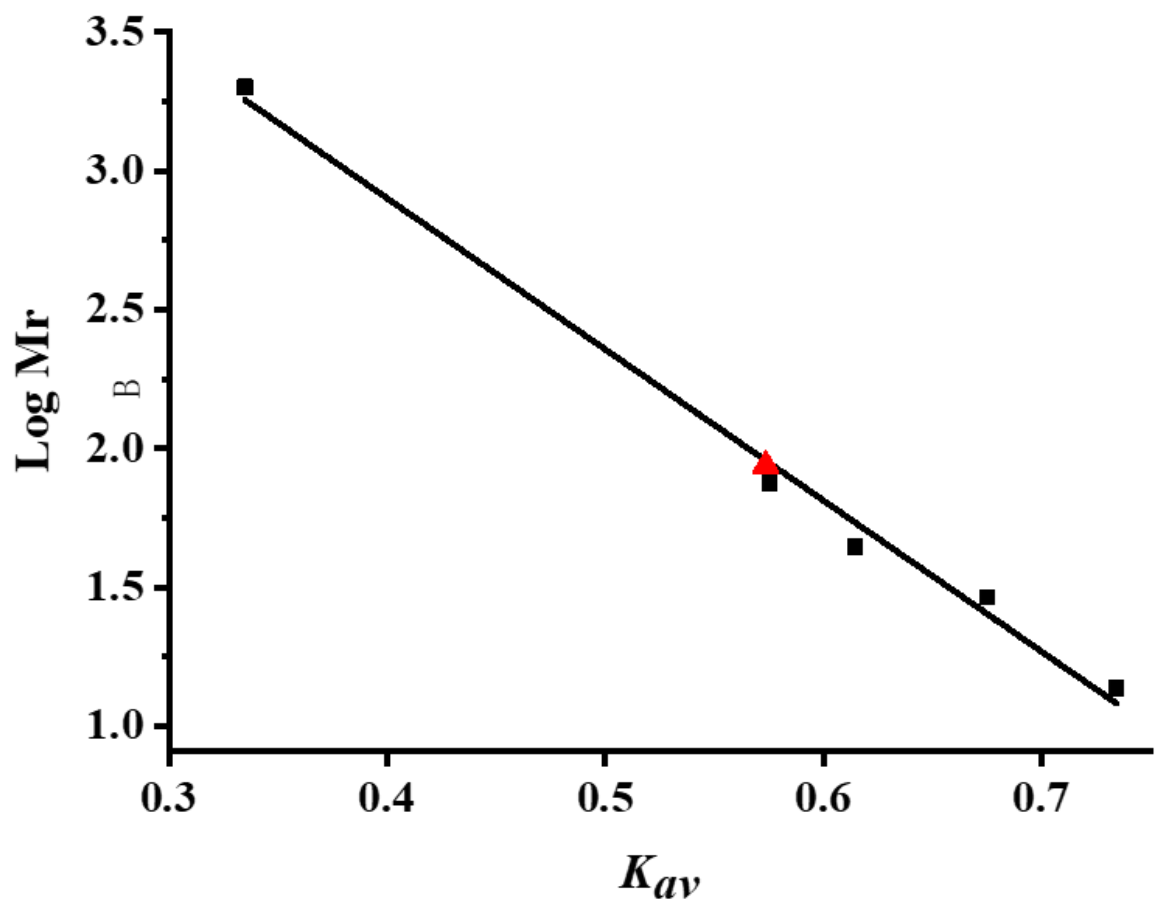

Figure S5. A plot of log molecular weight versus elution coefficient $K_{a v}$ for protein standards. His6HuHF (red triangle) was estimated to have a molecular weight of $86000 \pm 700 \mathrm{Da}(\mathrm{n}=3)$. 


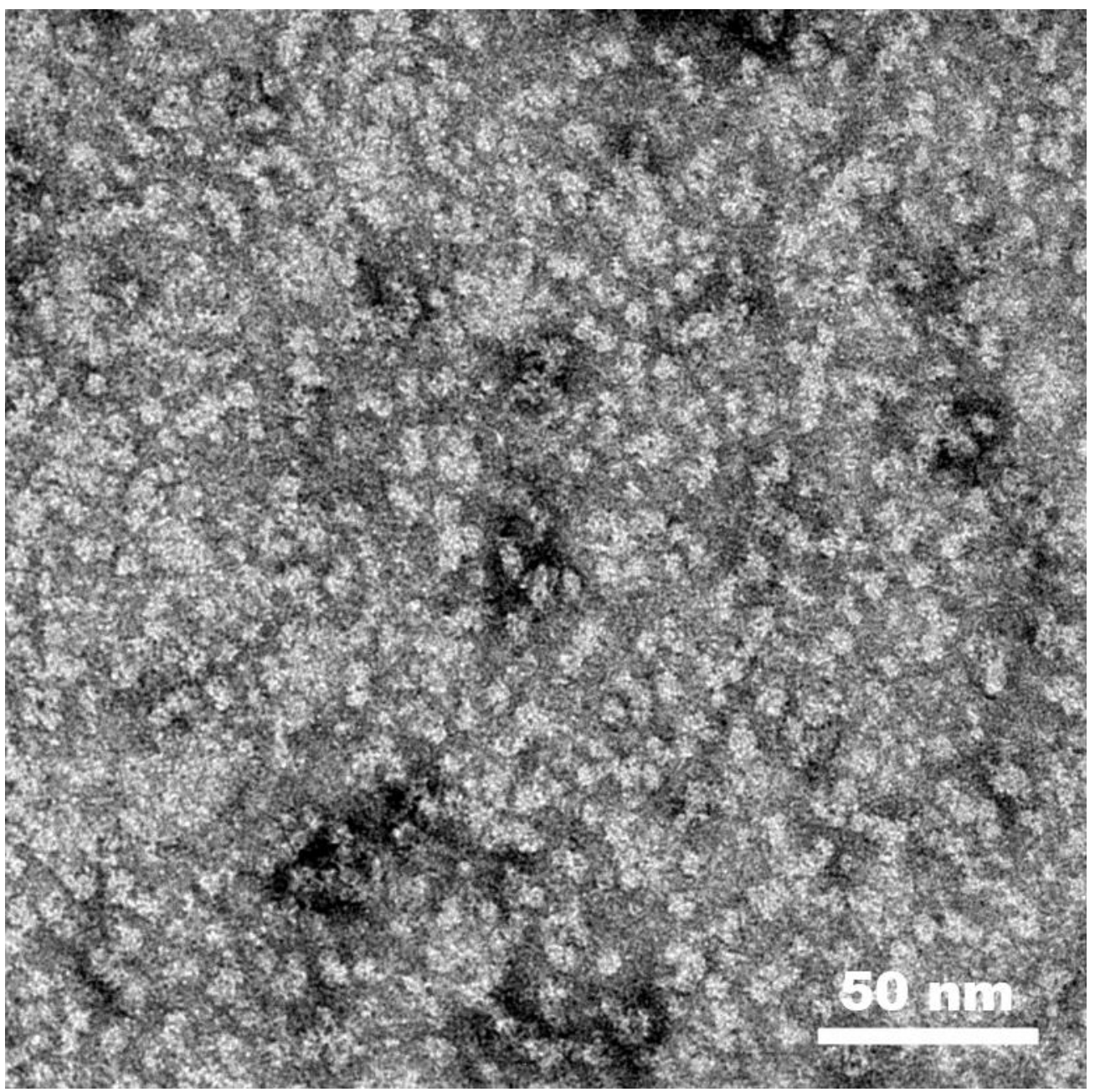

Figure S6. TEM image of purified $\mathrm{His}_{6}-\mathrm{HuHF}$ tetramer. 


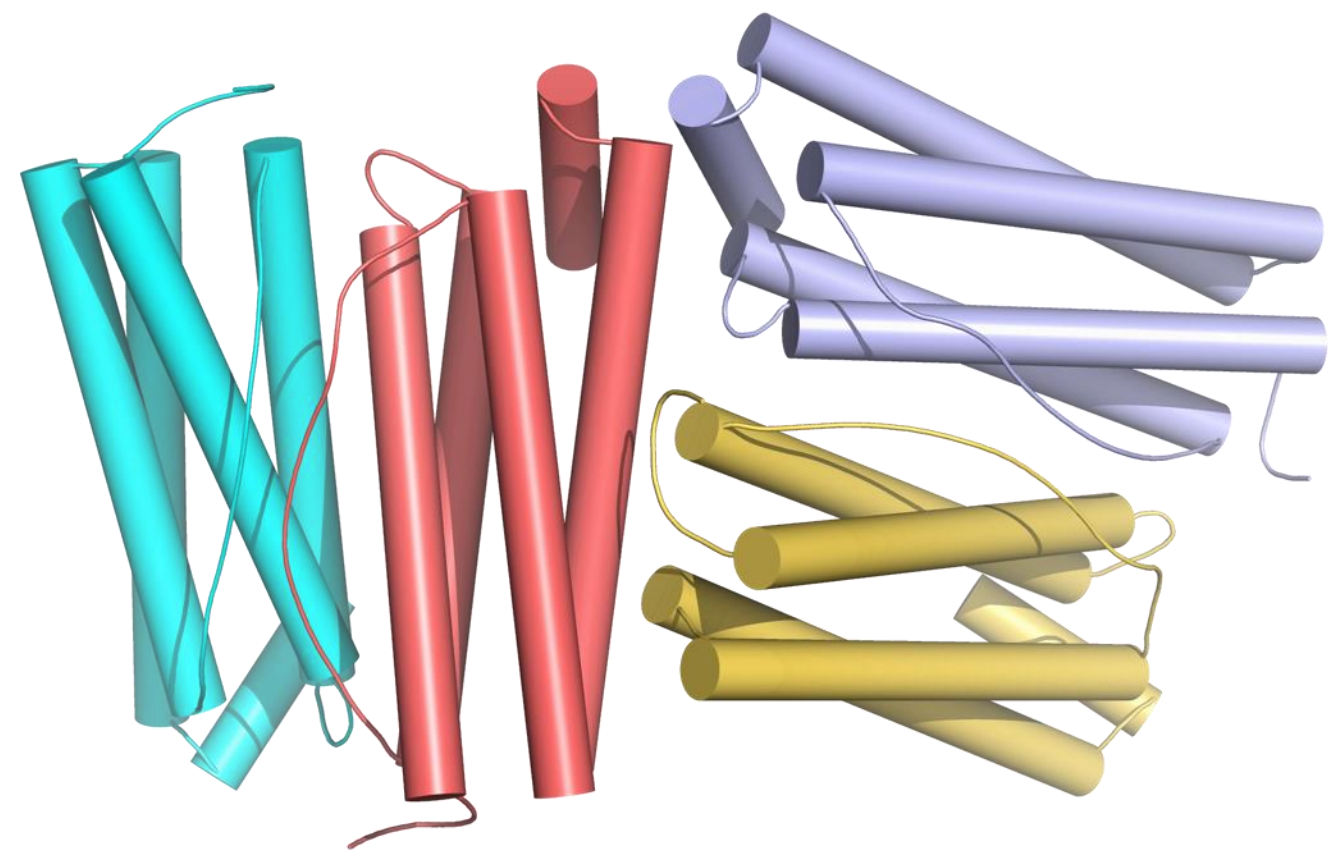

Figure S7. The proposed structure of $\mathrm{His}_{6}$-HuHF tetramer. 


\section{kDa Lane 1 M Lane 2 Lane 3 Lane 4}

669

440

232

140

66

Figure S8. Native-PAGE analyses of $\mathrm{His}_{6}-\mathrm{HuHF}$ assemble into protein nanocage induced by $\mathrm{Ni}^{2+}$. Lane 1: His6-HuHF without $\mathrm{Ni}^{2+}$; Lane 2: His6-HuHF with 6 equivalents $\mathrm{Ni}^{2+}$ of 24-meric ferritin; Lane 3: $\mathrm{His}_{6}-\mathrm{HuHF}$ with 12 equivalents $\mathrm{Ni}^{2+}$ to 24-meric ferritin; Lane 4: His 6 -HuHF with 24 equivalents $\mathrm{Ni}^{2+}$ to $24-$ meric ferritin. 


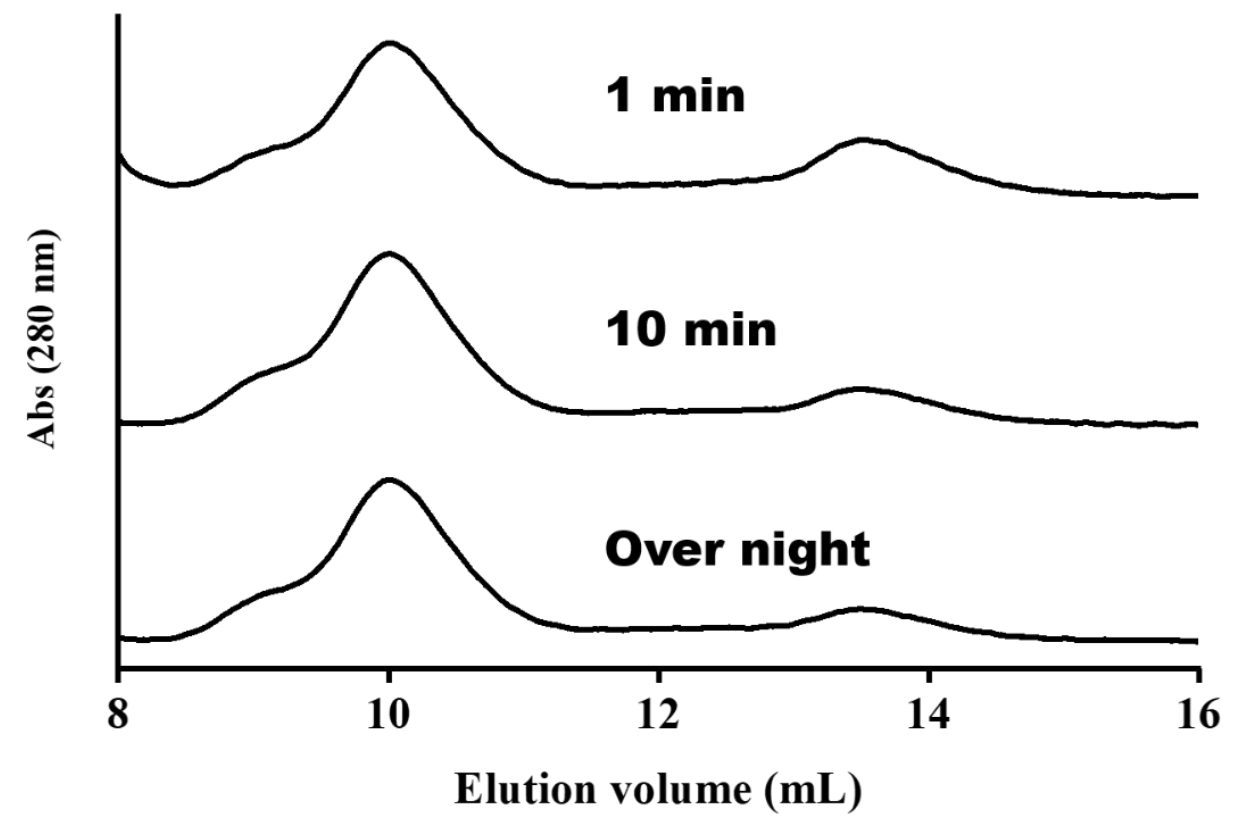

Figure S9. The conversion kinetics of His6-HuHF tetramers into protein nanocage in the presence of $\mathrm{Ni}^{2+}$ at a $\mathrm{Ni}^{2+} /$ protein nanocage ratio of 24 to 1 at $\mathrm{pH} 7.5$. 

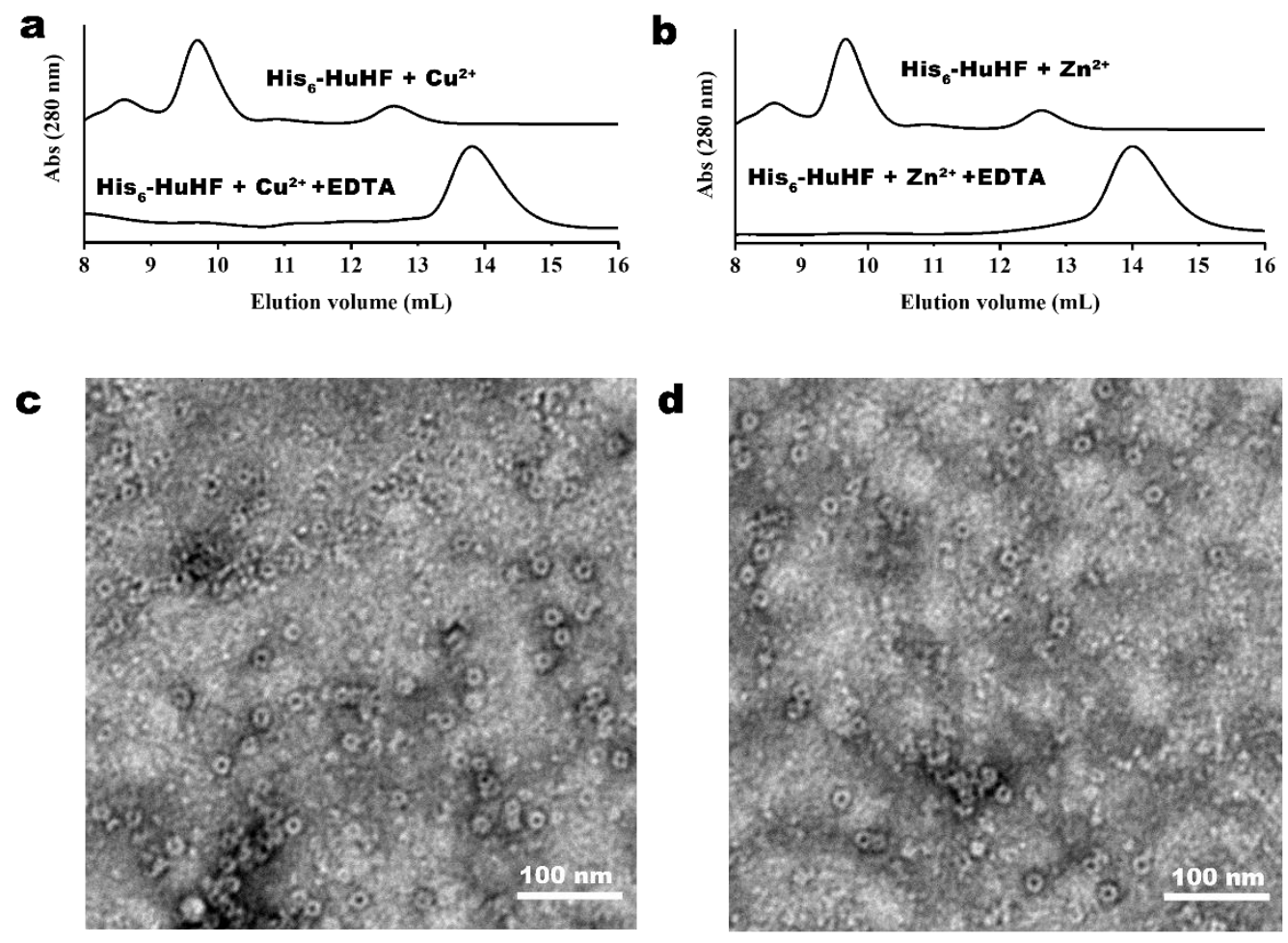

Figure S10. (a) High-resolution gel filtration chromatography analyses revealed that His6-HuHF tetramers re-assemble into protein nanocage in the presence of $\mathrm{Cu}^{2+}$ at a $\mathrm{Cu}^{2+} /$ protein nanocage ratio of 24 to 1 at $\mathrm{pH} 7.5$, while the formed protein nanocage dis-assemble into protein tetramers again upon treatment with EDTA. (b) $\mathrm{Zn}^{2+}$ also can trigger His6-HuHF tetramers re-assemble into protein nanocage under the same experimental conditions as $\mathrm{Cu}^{2+}$, and the addition of EDTA likewise caused such form protein nanocage to disassemble into protein tetramers. (c) TEM image of reconstituted $\mathrm{His}_{6}-\mathrm{HuHF}$ nanocage induced by $\mathrm{Cu}^{2+}$. (d) TEM image of reconstituted $\mathrm{His}_{6}-\mathrm{HuHF}$ nanocage induced by $\mathrm{Zn}^{2+}$. 


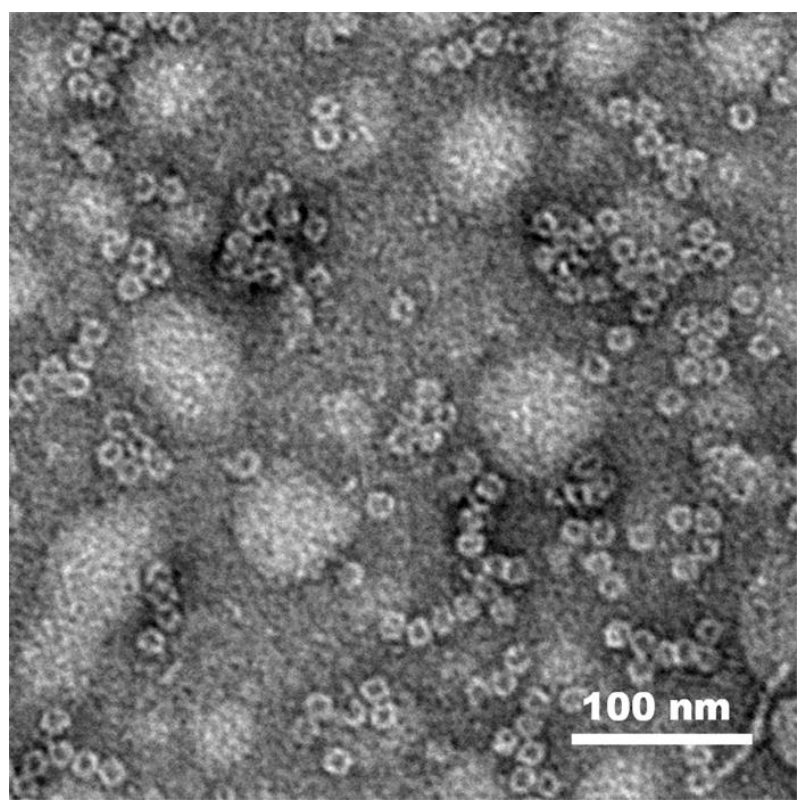

Figure S11. TEM image of reconstituted His 6 -HuHF nanocage induced by $\mathrm{pH}$ at 10.0. 

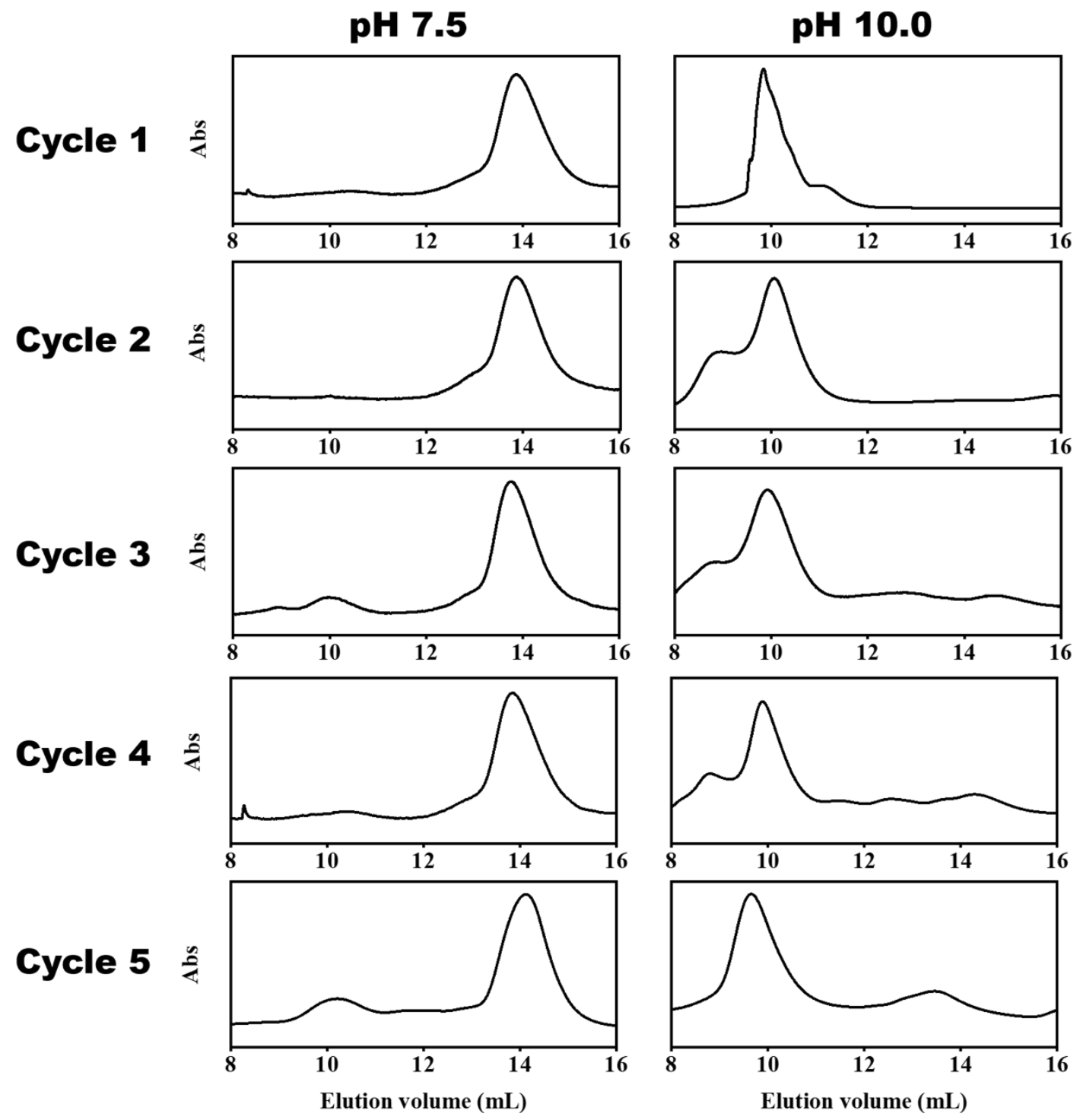

Figure S12. High-resolution gel filtration chromatography analyses of five cycles between assembly and disassembly of $\mathrm{His}_{6}-\mathrm{HuHF}$ induced by a change in $\mathrm{pH}$ from 7.5 and 10.0. 

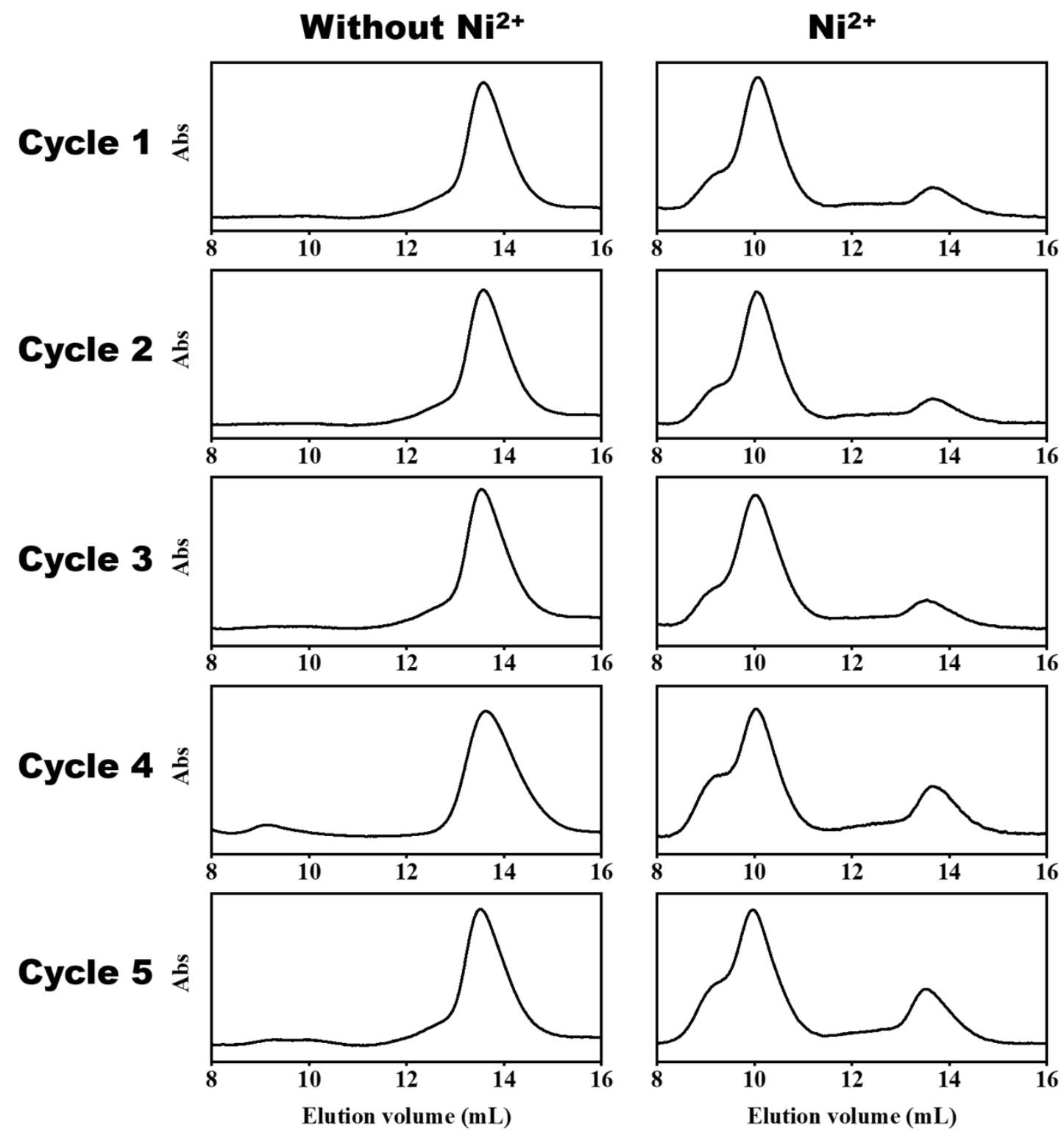

Figure S13. High-resolution gel filtration chromatography analyses of five cycles between assembly and disassembly of $\mathrm{His}_{6}-\mathrm{HuHF}$ induced by $\mathrm{Ni}^{2+} /$ EDTA (Left column: The initial protein or assembled 24-meric $\mathrm{His}_{6}-\mathrm{HuHF}$ induced by $\mathrm{Ni}^{2+}$ then treated with EDTA; Right column: Assembled $\mathrm{His}_{6}-\mathrm{HuHF}$ induced by $\mathrm{Ni}^{2+}$ ). 

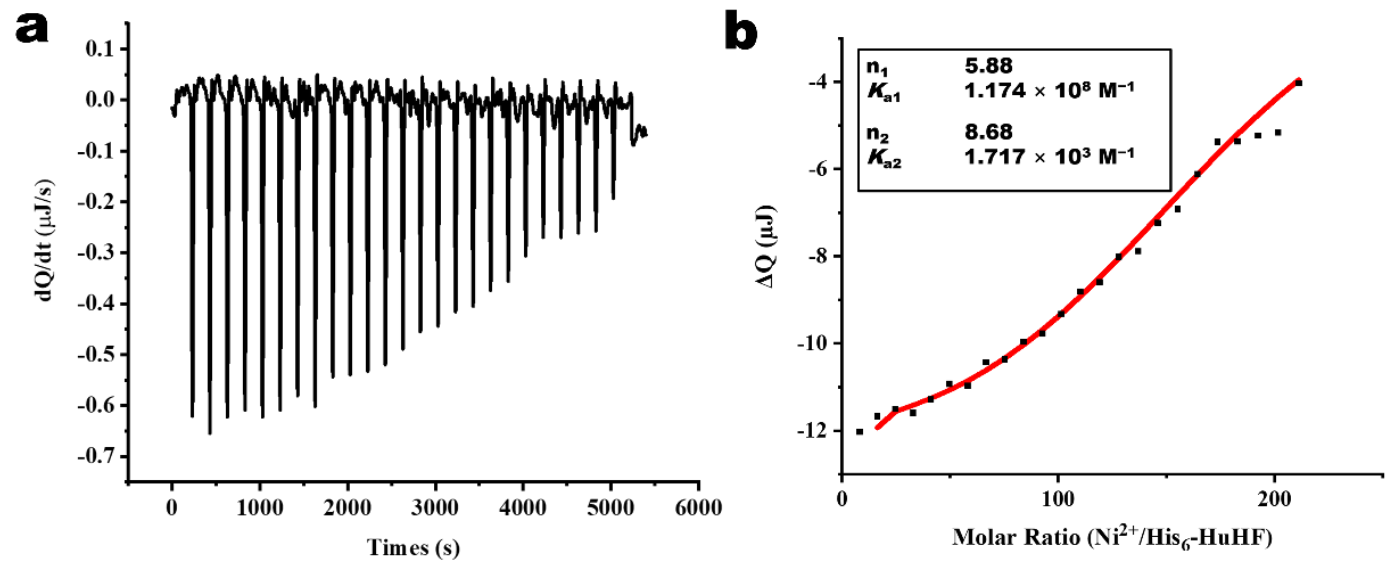

Figure S14. (a) Raw data for subsequent $50 \mu \mathrm{L}$ injections of $300 \mu \mathrm{M} \mathrm{NiSO}_{4}$ into the cell containing $2.0 \mu \mathrm{M}$ His 6 - $\mathrm{HuHF}$ at $25^{\circ} \mathrm{C}$ in $20 \mathrm{mM}$ Tris, $\mathrm{pH}$ 7.5. Integrated heat changes for each injection were shown after subtraction of the control injection. (c) A plot of integrated heat versus the number of injections. The solid line is the result of curve fitting to a model containing multiple metal binding sites with $\mathrm{n}_{1}=5.88, \mathrm{n}_{2}=8.68$ and $K a_{1}=1.174 \times 10^{8} \mathrm{M}^{-1}, K a_{2}=1.717 \times 10^{3} \mathrm{M}^{-1}$. 

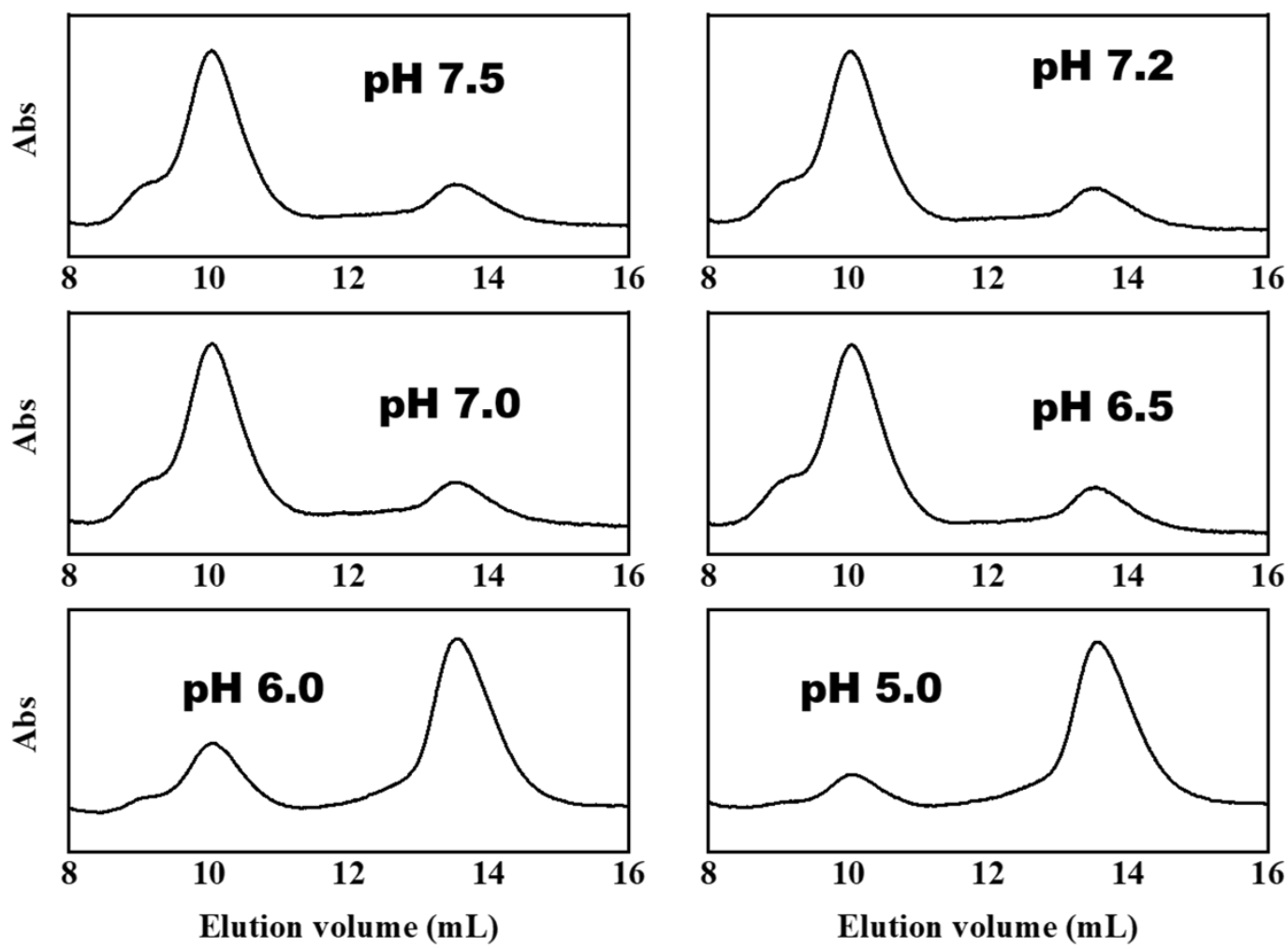

Figure S15. Effect of $\mathrm{pH}$ on the stability of the reconstituted 24-meric protein nanocage induced by $\mathrm{Ni}^{2+}$ as shown by high-resolution gel filtration chromatography analyses at different $\mathrm{pH}$ values (5.0, $6.0,6.5,7.0,7.2$, and 7.5). 


\section{a Native-PAGE}

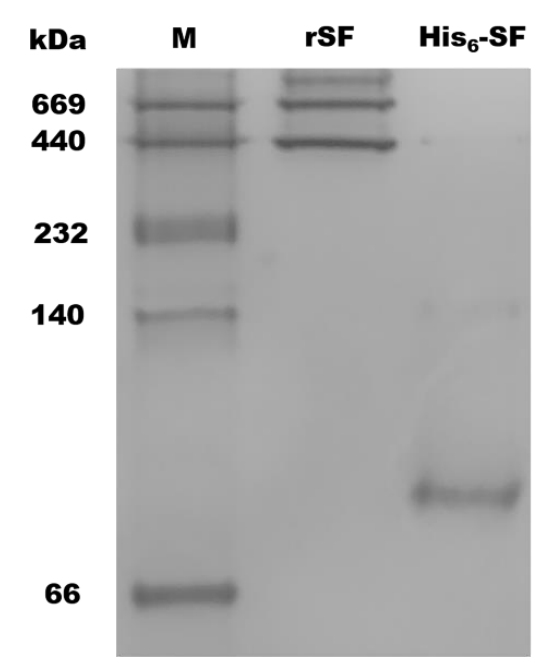

\section{SDS-PAGE}

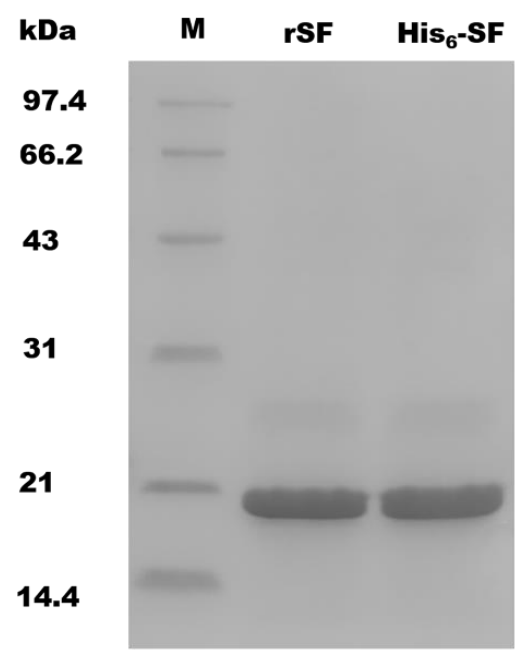

b

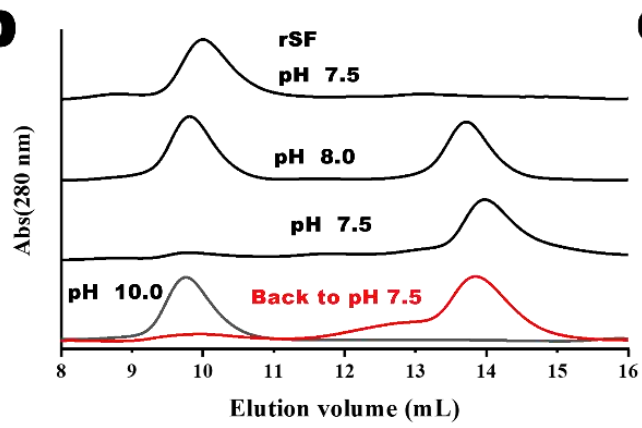

d

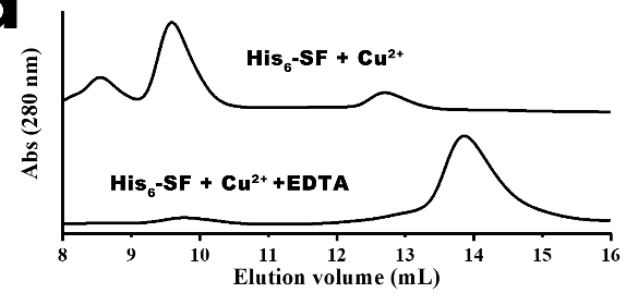

$\mathbf{C}$

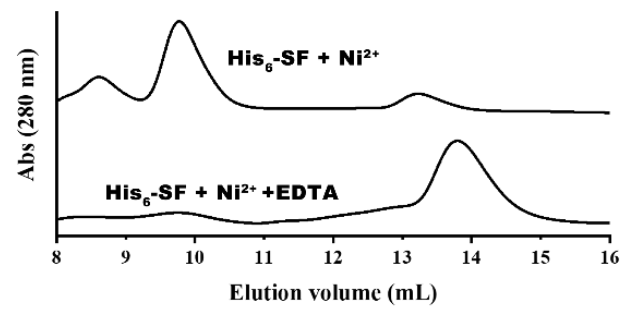

Figure S16. (a) Native -PAGE and SDS-PAGE analyses of rSF and its mutant His6-SF. (b) Selfassembly behavior of $\mathrm{His}_{6}-\mathrm{SF}$ at different $\mathrm{pH}$ values analyzed by high-resolution gel filtration chromatography. At $\mathrm{pH} 7.5$, most of protein species occur as protein tetramers. At $\mathrm{pH} 8.0$, nearly about $50 \%$ of the total convert into $24-$ mer protein nanocage. Upon increasing $\mathrm{pH}$ up to 10.0 , most of the protein species occurs as 24-meric protein nanocages. Upon adjusting $\mathrm{pH}$ from 10.0 back to 7.5, the 24-meric protein can also disassemble into tetramers (red line). (c) Nickel ions can induce most of His $_{6}$-SF tetramers to convert into protein nanocage, while EDTA can reverse such protein assembly. Almost similar results were obtained when $\mathrm{Cu}^{2+}(\mathrm{d})$ or $\mathrm{Zn}^{2+}(\mathrm{e})$ was used instead of $\mathrm{Ni}^{2+}$. 


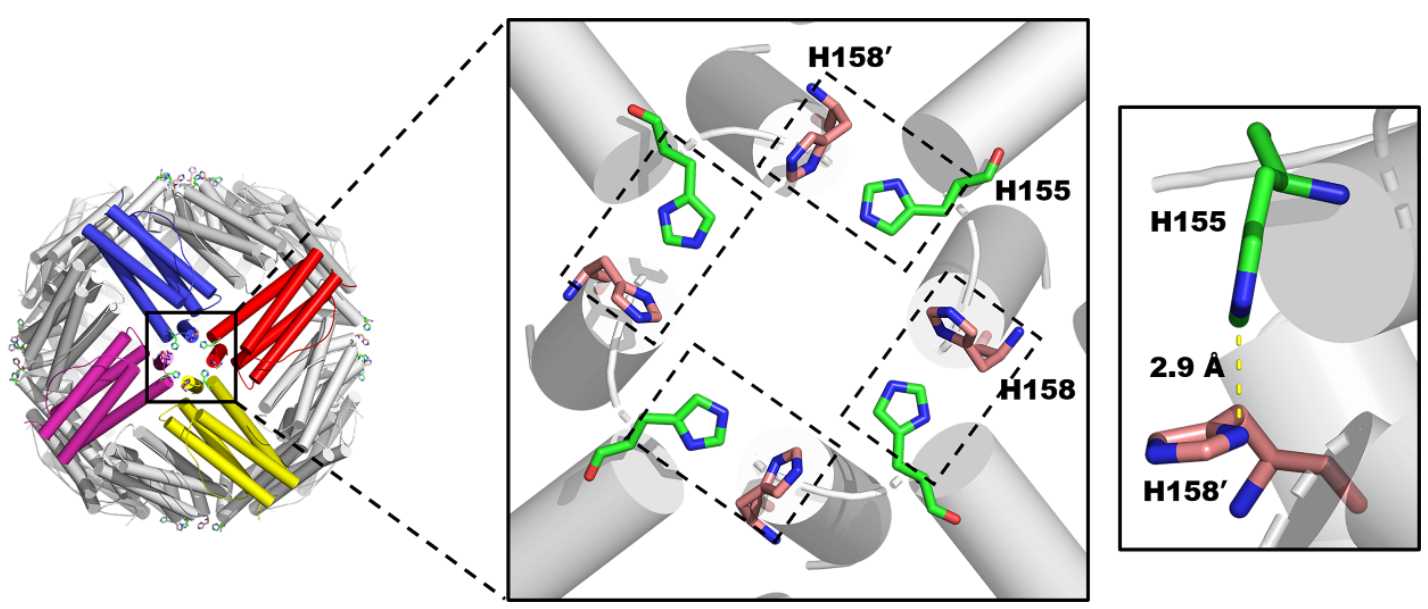

Figure S17. T-shaped $\pi-\pi$ interactions between $\mathrm{H} 155$ and H158 from two adjacent subunits at the $C_{4}$ interface of reconstituted His6-SF nanocage induced by $\mathrm{Ni}^{2+}$. 

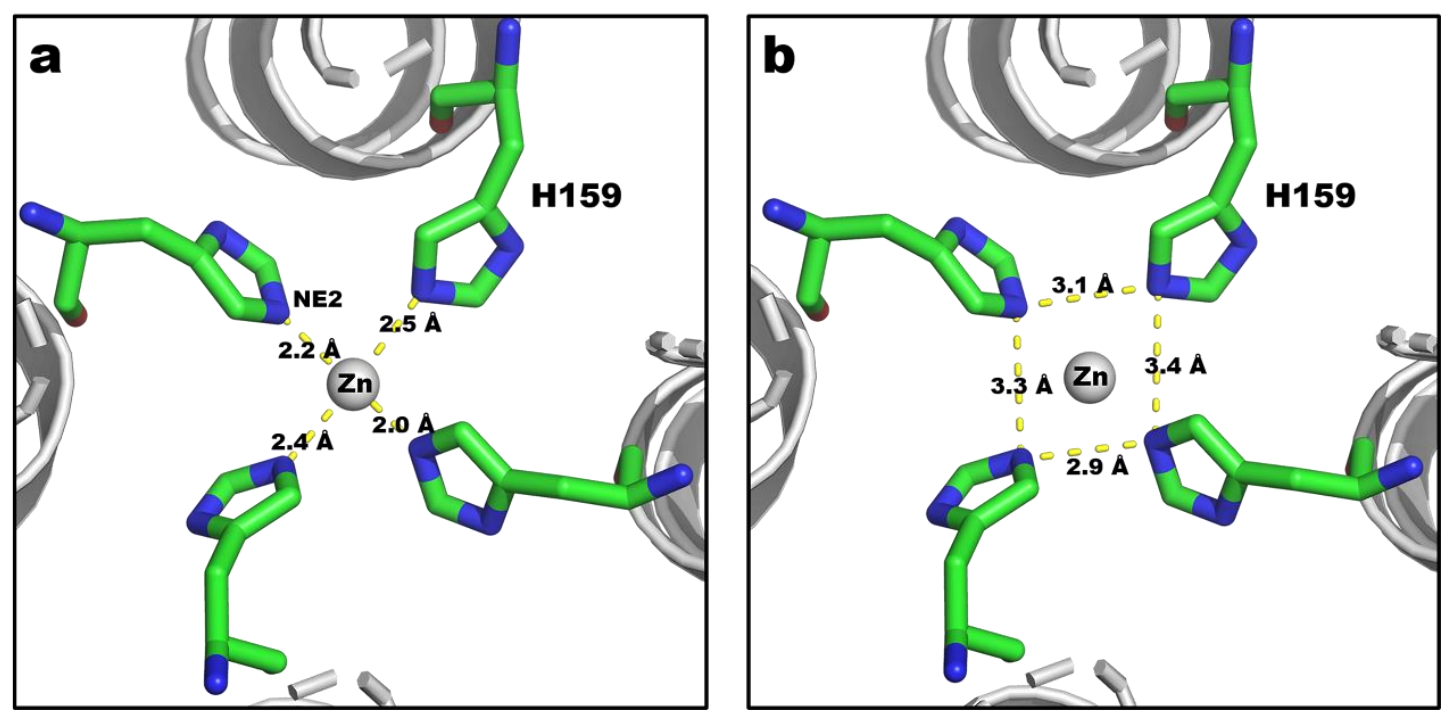

Figure S18. (a) The different distances between the zinc ion and NE2 of H159. (b) The different distances between the adjacent NE2 of H159. 


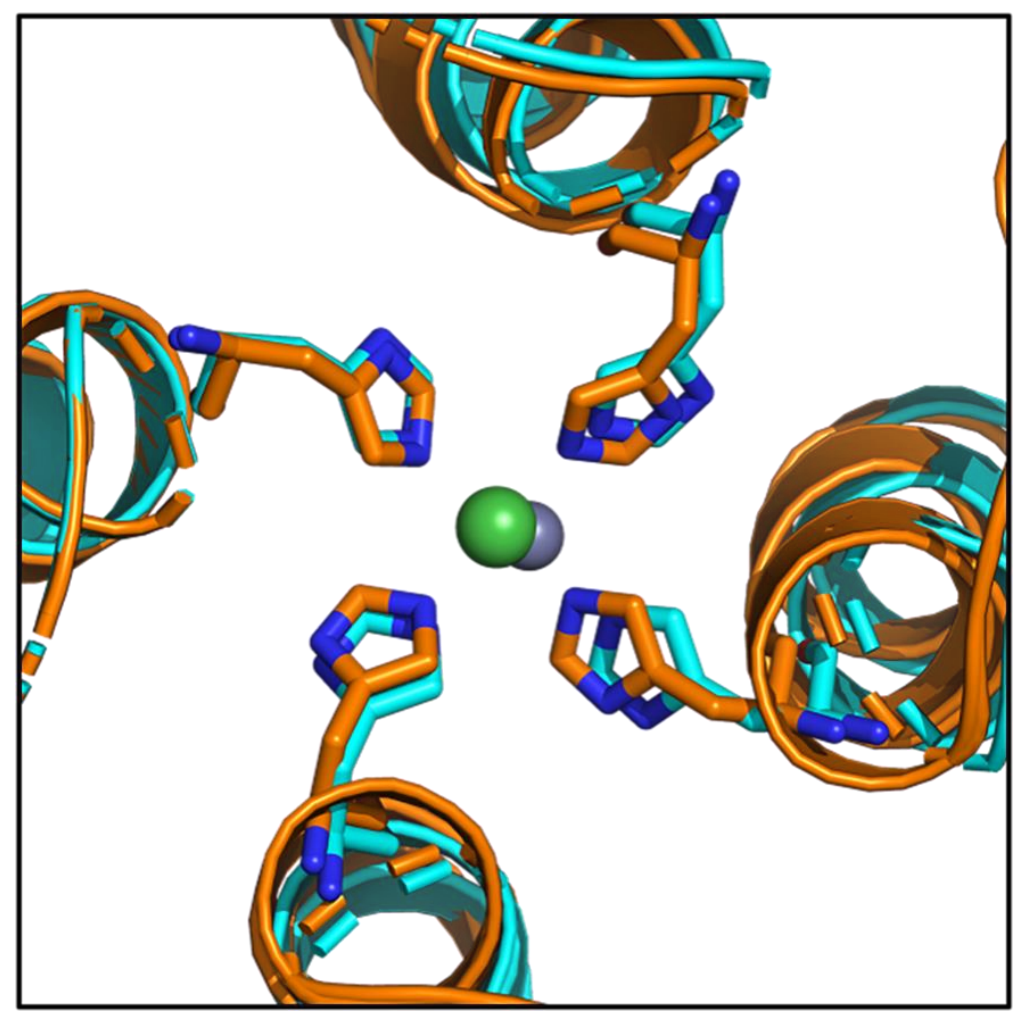

Figure S19. An overlay of the Ni-bound and Zn-bound His ${ }_{6}-\mathrm{SF}$ structures (Orange chain: Nibound His6-SF; Cyan chain: Zn-bound His6-SF; Green symbol: Ni²+; Gray symbol: $\mathrm{Zn}^{2+}$ ) . 

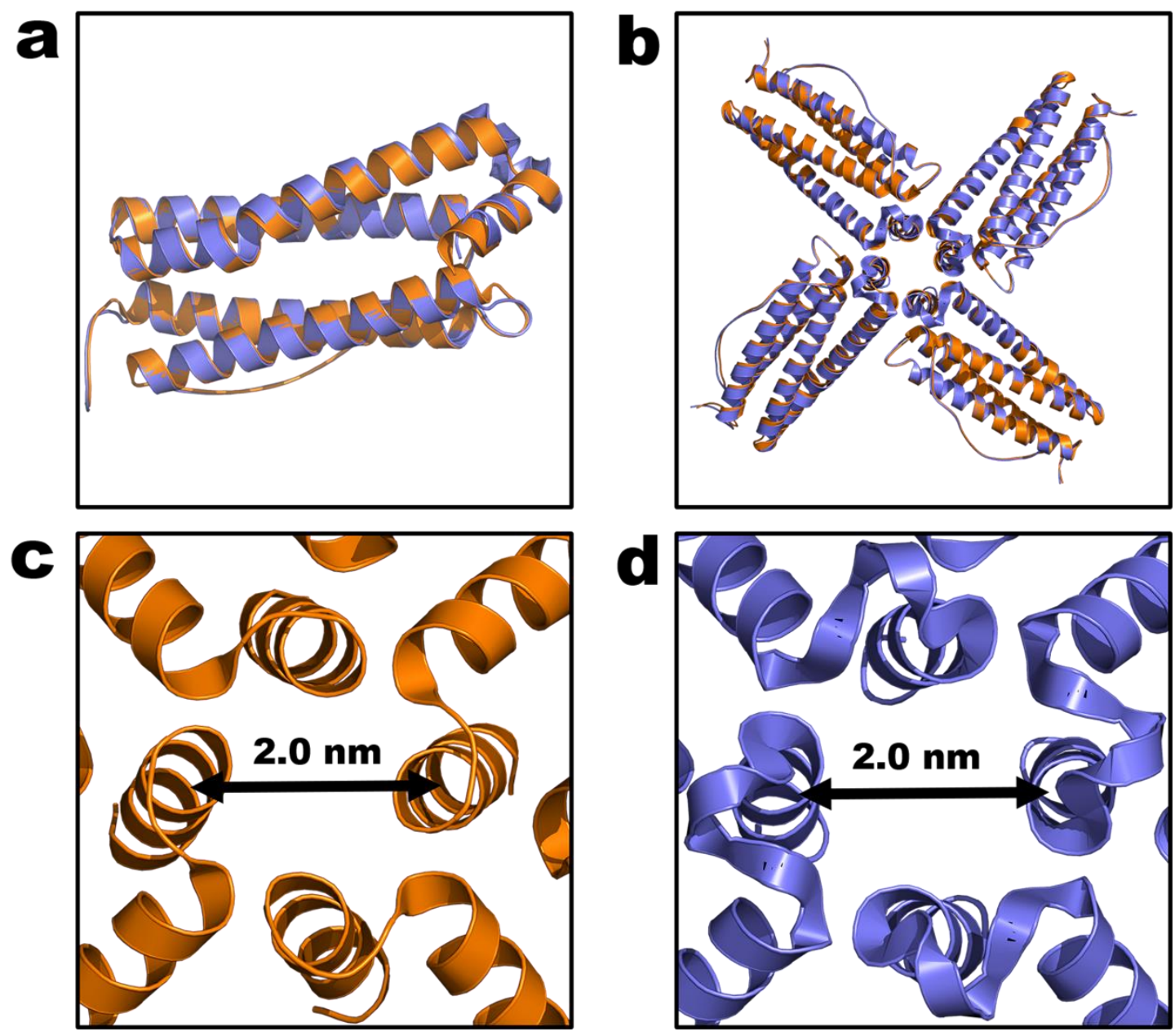

Figure S20. Comparison analysis of rHuHF and rSF crystal structures. (a) Alignment of rHuHF and rSF subunits. (b) Alignment of the $C_{4}$ axes of 24-meric rHuHF and rSF. (c) The diameter of the $C_{4}$ axis aperture of rSF is $2.0 \mathrm{~nm}$. (d) The diameter of the $C_{4}$ axis aperture of rHuHF is also $2.0 \mathrm{~nm}$. 


\section{Supplementary Table}

Table S1 Crystallographic statistics

\begin{tabular}{|c|c|c|}
\hline Crystal & $\mathrm{His}_{6}-\mathrm{SF} / \mathrm{Zn}^{2+}$ & $\mathrm{His}_{6}-\mathrm{SF} / \mathrm{Ni}^{2+}$ \\
\hline \multicolumn{3}{|l|}{ Data collection } \\
\hline Beamline & BL19U1 & BL19U1 \\
\hline Wavelength $(\AA)$ & 0.97892 & 0.97892 \\
\hline Space group & I 4 & I 4 \\
\hline \multicolumn{3}{|l|}{ Unit cell } \\
\hline a, b, c (̊) & $126.1,126.1,176.7$ & $126.1,126.1,176.7$ \\
\hline$\alpha, \beta, \gamma\left({ }^{\circ}\right)$ & $90.0,90.0,90.0$ & $90.0,90.0,90.0$ \\
\hline aResolution $(\AA)$ & $19.80-2.60(2.70-2.60)$ & $19.80-2.80(2.90-2.80)$ \\
\hline aRedundancy & $6.8(7.0)$ & $4.6(4.7)$ \\
\hline${ }^{\mathrm{a} C o m p l e t e n e s s ~(\%) ~}$ & $99.7(100)$ & $99.6(100)$ \\
\hline${ }^{\mathrm{a}} / / \sigma I$ & $16.4(2.4)$ & $7.5(2.2)$ \\
\hline a,b $R_{\text {merge }}$ & $0.136(0.688)$ & $0.167(0.516)$ \\
\hline a,c $R_{p i m}$ & $0.056(0.281)$ & $0.085(0.257)$ \\
\hline $\begin{array}{l}{ }^{\mathrm{d}} \mathrm{CC}_{1 / 2} \text { of the highest resolution } \\
\text { shell }\end{array}$ & $0.989(0.785)$ & $0.959(0.789)$ \\
\hline \multicolumn{3}{|l|}{ Refinement } \\
\hline Unique reflections & 42132 & 33758 \\
\hline Number of Atoms & 8267 & 8254 \\
\hline Protein & 8232 & 8232 \\
\hline $\mathrm{Fe}^{3+}$ & 12 & 6 \\
\hline $\mathrm{Zn}^{2+}$ & 7 & \\
\hline $\mathrm{Ni}^{2+}$ & 0 & 6 \\
\hline $\mathrm{H}_{2} \mathrm{O}$ & 16 & 10 \\
\hline${ }^{\mathrm{e}} R_{\text {work }} / R_{\text {free }}$ & $0.194 / 0.272$ & $0.194 / 0.269$ \\
\hline Wilson B-factor $\left(\AA^{2}\right)$ & 36.1 & 35.7 \\
\hline \multicolumn{3}{|l|}{$B$-factors $\left(\AA^{2}\right)$} \\
\hline Protein & 50 & 27 \\
\hline
\end{tabular}


Metal

$\mathrm{H}_{2} \mathrm{O}$

R.m.s. deviations

Bond lengths (£)

Bond angles $\left({ }^{\circ}\right)$

Ramachandran plot (\%)

Favored

Allowed

Outliers $\begin{array}{ll}0.015 & 0.008\end{array}$

1.46

0.93

96.5

96.7

3.1

3.0

0.41

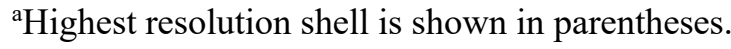

${ }^{\mathrm{b}} R_{\text {merge }}=\sum_{h k l} \sum_{j}\left|I_{j}(h k l)-<\mathrm{I}(h k l)>\right| / \sum_{\text {hkl }} \sum_{j} I_{j}(h k l)$, where $I$ is the intensity of reflection.

${ }^{\mathrm{c}} R_{p i m}=\sum_{h k l}[1 /(\mathrm{N}-1)]^{1 / 2} \sum_{j}\left|I_{j}(h k l)-<\mathrm{I}(h k l)>\right| / \sum_{h k l} \sum_{j} I_{j}(h k l)$, where $\mathrm{N}$ is the redundancy of the dataset. ${ }^{\mathrm{d}} \mathrm{CC}_{1 / 2}$ is the correlation coefficient of the half datasets.

${ }^{\mathrm{e}} R_{\text {work }}=\sum_{h k l}|| F_{o b s}|-| F_{c a l c}|| / \sum_{h k l}\left|F_{o b s}\right|$, where $F_{o b s}$ and $F_{c a l c}$ is the observed and the calculated structure factor, respectively. $\mathrm{R}_{\text {free }}$ is the cross-validation $\mathrm{R}$ factor for the test set of reflections $(5 \%$ of the total) omitted in model refinement. 
Table S2. Comparison of encapsulation efficiency of different encapsulate methods

\begin{tabular}{lcc}
\hline \multirow{2}{*}{ Encapsulation methods } & \multicolumn{2}{c}{ Loading Capacity } \\
\cline { 2 - 3 } & Curcumin/Protein nanocage & Doxorubicin/ Protein nanocage \\
\hline PRTN & $83.4 \pm 3.2$ & $92.6 \pm 1.3$ \\
$\mathrm{Ni}^{2+}$-MRTN (His6-HuHF) & $62.1 \pm 2.7$ & $73.0 \pm 2.0$ \\
$\mathrm{Cu}^{2+}$-MRTN (His6-HuHF) & $56.2 \pm 2.6$ & $64.5 \pm 1.9$ \\
$\mathrm{Zn}^{2+}$-MRTN(His6-HuHF) & $28.2 \pm 5.9$ & $33.3 \pm 0.8$ \\
Acid-denatured (rHuHF) & $17.2 \pm 2.4$ & $27.2 \pm 2.8$ \\
\hline
\end{tabular}

